\title{
Core-Shell Structure of Gold Nanoparticles with Inositol Hexaphosphate Nanohybrids for Label-Free and Rapid Detection by SERS Nanotechnology
}

\author{
Andreas H. H. Mevold, ${ }^{1}$ Jin-Yuan Liu, ${ }^{1}$ Li-Ying Huang, ${ }^{1}$ \\ Hung-Liang Liao, ${ }^{1}$ Ming-Chien Yang, ${ }^{1}$ Tzu-Yi Chan, ${ }^{2}$ Kuan-Syun Wang, \\ Juen-Kai Wang,, ${ }^{3,4}$ Yuh-Lin Wang, ${ }^{4,5}$ and Ting-Yu Liu ${ }^{2}$ \\ ${ }^{1}$ Department of Materials Science and Engineering, National Taiwan University of Science and Technology, Taipei 106, Taiwan \\ ${ }^{2}$ Department of Materials Engineering, Ming Chi University of Technology, New Taipei City 24301, Taiwan \\ ${ }^{3}$ Center for Condensed Matter Sciences, National Taiwan University, Taipei 10617, Taiwan \\ ${ }^{4}$ Institute of Atomic and Molecular Sciences, Academia Sinica, Taipei 10617, Taiwan \\ ${ }^{5}$ Department of Physics, National Taiwan University, Taipei 10617, Taiwan
}

Correspondence should be addressed to Ming-Chien Yang; myang@mail.ntust.edu.tw and Ting-Yu Liu; tyliu0322@gmail.com

Received 5 February 2015; Accepted 16 March 2015

Academic Editor: Ping Yang

Copyright ( 2015 Andreas H. H. Mevold et al. This is an open access article distributed under the Creative Commons Attribution License, which permits unrestricted use, distribution, and reproduction in any medium, provided the original work is properly cited.

Gold nanoparticles bound with inositol hexaphosphate $\left(\mathrm{IP}_{6}\right)\left(\mathrm{AuNPs} / \mathrm{IP}_{6}\right)$ were prepared by in situ reduction of various concentrations of $\mathrm{IP}_{6}(0 \sim 320 \mu \mathrm{M})$ through modified Frens method for surface-enhanced Raman scattering (SERS) detection. The resultant AuNPs/ $\mathrm{IP}_{6}$ were subject to characterization including UV/Vis spectroscopy, transmission electron microscopy (TEM), dynamic light scattering (DLS), zeta potential, and X-ray photoelectron spectroscopy (XPS). The results showed that AuNPs with $65 \mu \mathrm{M}$ of IP ${ }_{6}$ would result in a core AuNPs-shell (IP ${ }_{6}$ layer) structure, which exhibited the strongest SERS signal, due to the "hot spot effect" generated from the 1-2 nm interparticle gaps of AuNPs/IP $\mathrm{IP}_{6}$ nanohybrids (ionic interaction of $\mathrm{IP}_{6}$ and $\mathrm{Au}^{+}$). Furthermore, the reaction kinetics of $\mathrm{Au}$ and $\mathrm{IP}_{6}$ were also investigated in this work. Higher concentration of $\operatorname{IP}_{6}(190$ and $260 \mu \mathrm{M})$ will make AuNPs become irregularly shaped, because $\mathrm{IP}_{6}$ is a basic salt and served as a $\mathrm{pH}$ mediator. The morphology and distribution of AuNPs were greatly improved by addition of $65 \mu \mathrm{M}$ of $\mathrm{IP}_{6}$. This novel AuNPs/IP ${ }_{6}$ nanohybrid showed great stability and Raman enhancement. It is promising in the application of rapid and label-free biological detection of bacteria or tumor cells.

\section{Introduction}

Raman scattering was discovered by C. V. Raman in 1928 and SERS technology was developed by Fleischman and others in 1974 [1]. In recent years, SERS has been employed for label-free sensing of bacteria such as Escherichia coli (E. coli) or various molecules, exploiting its tremendous enhancement of the Raman signal. Gold and silver nanoparticles are widely used in this field [2-4], because they produce localized surface plasma resonance (LSPR), which can increase the intensity of the Raman signal by at least $10^{9}$. Gold and silver nanoparticles have unique optical, electrical, and magnetic properties because of their particle size and morphology.
Therefore controlling the size and morphology is important when synthesizing nanoparticles [5-7]. Gold and silver nanoparticles (NPs) increase Raman signal under specific frequency because LSPR produces electromagnetic field, which will increase the Raman signal of the absorbed molecule. If we further limit the space between these metal nanoparticles at 1-2 nm, it will produce "hot spot" effect, which will further increase the intensity of the SERS signals [2-4]. Therefore these materials showed promising potential in the application of SERS $[8,9]$ and biosensing $[10,11]$.

Inositol hexaphosphate $\left(\mathrm{IP}_{6}\right)$ is known as phytic acid sodium salt, a naturally derived material. It could be used to prepare oral cleansing agent, water treatment agent, food 


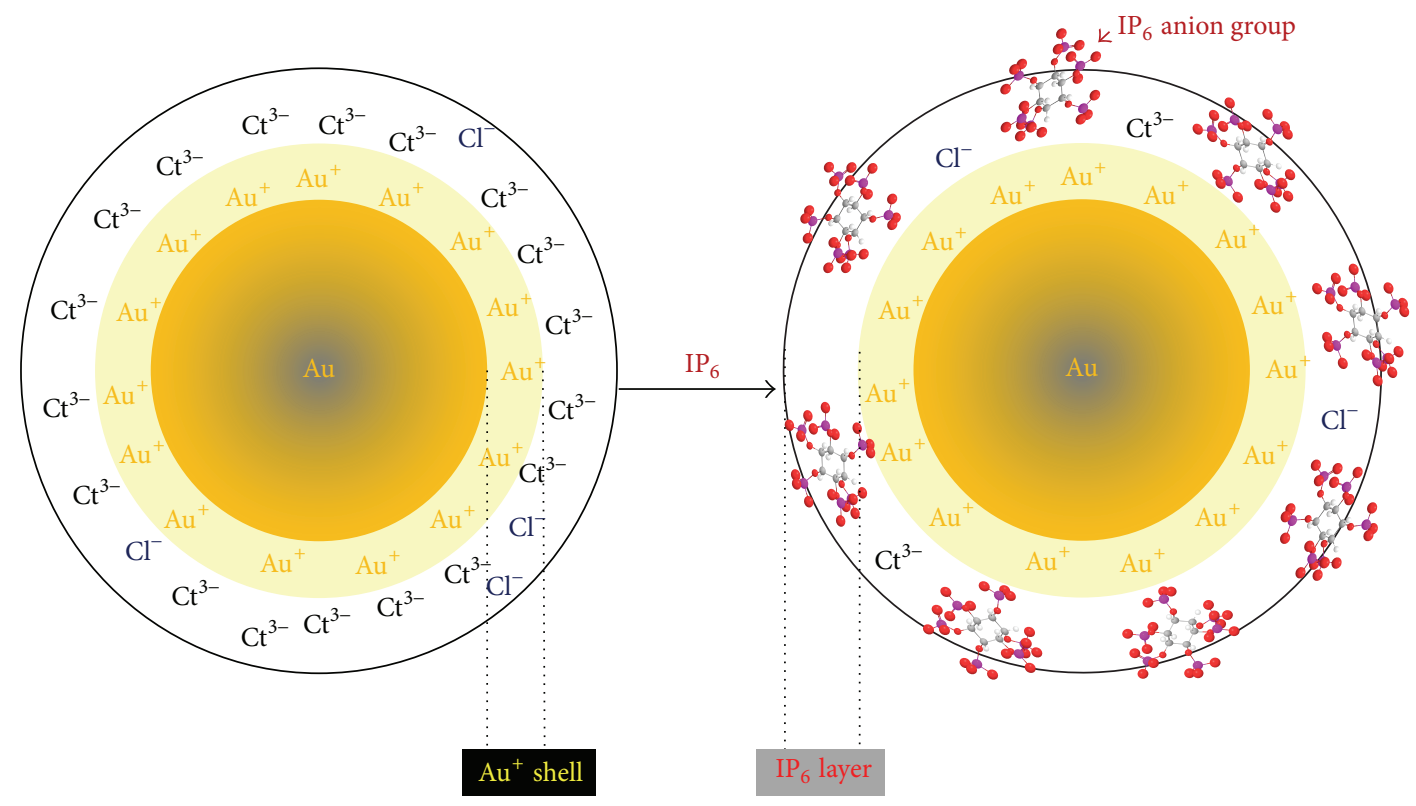

SCHEME 1: Schematic figure of core-shell structure of AuNPs/IP ${ }_{6}$ nanohybrids.

additive, and so on because of its nontoxic and natural properties [12]. The structure of $\mathrm{IP}_{6}$ contains six phosphate acid groups (negatively charged) which are able to link with metal particles and have good absorption capability. Therefore we will employ $\mathrm{IP}_{6}$ as a tunable cross linker (or spacer) to obtain AuNPs with a distance between each other at $1-2 \mathrm{~nm}$.

In this work, AuNPs were produced by a procedure developed by Frens et al. in 1973 using sodium citrate to reduce $\mathrm{HAuCl}_{4}$ to produce monodispersed AuNPs. In this present work, $\mathrm{IP}_{6}$ was added during the reduction procedure and its adsorption onto the AuNPs led to the final product AuNPs/ $\mathrm{IP}_{6}$. The final product will be further tested in the application of SERS for detecting microorganism Staphylococcus aureus.

\section{Experimental Procedure}

2.1. Materials. Inositol hexaphosphate $\left(\mathrm{IP}_{6}\right)$, sodium citrate dihydrate $\left(\mathrm{Na}_{3} \mathrm{Ct} \cdot 2 \mathrm{H}_{2} \mathrm{O}\right)$, hydrogen tetrachloroaurate (III) trihydrate $\left(\mathrm{HAuCl}_{4} \cdot 3 \mathrm{H}_{2} \mathrm{O}\right)$, and sodium hydroxide $(\mathrm{NaOH})$ were purchased from Sigma-Aldrich. Nitric acid $\left(\mathrm{HNO}_{3}\right)$ was purchased from Scharlau, Spain. Silicon oil was purchased from Choneye Pure Chemical. Luria-Bertani (LB) broth was purchased from Difco. Bacteriological agar was obtained from Oxoid Ltd., UK. All glassware was cleaned with aqua-regia and rinsed with deionized water prior to the experiment. Staphylococcus aureus was obtained from Super Laboratory Co., Taiwan.

2.2. Synthesis of Gold Nanoparticles. The gold nanoparticles were synthesized on the basis of the method developed by Frens et al. Table 1 lists the solution for preparing AuNPs/ $/ \mathrm{IP}_{6}$ by mixing $0.01 \% \mathrm{HAuCl}_{4}$ with $1.0 \mathrm{mM} \mathrm{IP}_{6}$ stock solution. When the solutions were boiling for $10 \mathrm{~min}, 3.5 \mathrm{~mL}$ of $1 \%$
TABLE 1: The solution compositions for the preparation of $\mathrm{HAuCl}_{4} / \mathrm{IP}_{6}$.

\begin{tabular}{lccc}
\hline Sample & $0.01 \% \mathrm{HAuCl}_{4}(\mathrm{~mL})$ & $1 \mathrm{mM} \mathrm{IP}_{6}(\mathrm{~mL})$ & $\mathrm{H}_{2} \mathrm{O}(\mathrm{mL})$ \\
\hline A0 & 70 & 0 & 35 \\
A1 & 70 & 2.8 & 32.2 \\
A2 & 70 & 7 & 28 \\
A3 & 70 & 14 & 21 \\
A4 & 70 & 21 & 14 \\
A5 & 70 & 28 & 7 \\
A6 & 70 & 35 & 0 \\
\hline
\end{tabular}

sodium citrate was then added drop wisely. During the reaction, the color of the solution turned from light yellow color to brick red color. The reaction completed when the color no longer changed and the final solution result was referred to here as gold colloids. The samples of $\mathrm{HAuCl}_{4} / \mathrm{IP}_{6}$ solutions were analyzed using TEM and DLS as described in the following section. Scheme 1 depicts the core-shell structure of AuNPs/IP 6 nanohybrids.

2.3. Reaction Time for $\mathrm{HAuCl}_{4} / \mathrm{IP}_{6}$ Solutions. The reaction time of the gold colloids is the time required for the reaction of $\mathrm{HAuCl}_{4}$ and $\mathrm{IP}_{6}$ to be completed when the color no longer changes. The exhausted time for $\mathrm{HAuCl}_{4}$ was monitored according to the way developed by Ji et al. [13]. Temporal evolution of $\mathrm{HAuCl}_{4}$ was obtained by measuring the $\mathrm{pH} 10$ times before the exhaustion of $\mathrm{HAuCl}_{4}$ with $\mathrm{IP}_{6}$ and initial reaction rate was also obtained.

2.4. TEM of the AuNPS of the Gold Colloids. An aliquot of $5 \mu \mathrm{L}$ of the gold colloids described in Section 2.2 was placed on the copper grid and dried in the autoclave. Afterwards, 
TABLE 2: Wavelength and absorbance of AuNPs/IP ${ }_{6}$ in different concentrations of $\mathrm{IP}_{6}$.

\begin{tabular}{|c|c|c|c|c|c|}
\hline Sample & $\begin{array}{l}{\left[\mathrm{IP}_{6}\right]} \\
(\mu \mathrm{M})\end{array}$ & Wavelength 1 (nm) & Wavelength $2(\mathrm{~nm})$ & Absorbance 1 & Absorbance 2 \\
\hline A0 & 0 & 525 & - & 0.63 & - \\
\hline $\mathrm{A} 1$ & 26 & 524 & - & 0.66 & - \\
\hline A2 & 65 & 526 & - & 0.67 & - \\
\hline A3 & 130 & 534 & - & 0.59 & - \\
\hline A4 & 190 & 549 & 648 & 0.48 & 0.49 \\
\hline A5 & 260 & 549 & 725 & 0.35 & 0.32 \\
\hline A6 & 320 & 534 & 655 & 0.34 & 0.21 \\
\hline
\end{tabular}

they were placed in a copper grid box and analyzed using TEM (H7650, Hitachi, Japan) for the size distribution (diameter) and morphology of AuNPs.

2.5. Dynamic Light Scattering (DLS) of the Gold Colloids. The gold colloids $(1 \mathrm{~mL})$ were placed in a DLS cuvette followed by sonicating for $5 \mathrm{~s}$ before DLS (Nano ZS, Malvern Instruments, UK) analysis. Each sample was analyzed 3 times.

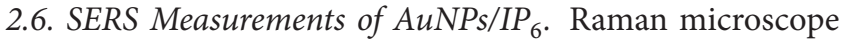
(HR800, Horiba, Japan) with He-Ne laser $(632.8 \mathrm{~nm})$ was used to detect the presence of $S$. aureus (ATCC 6538P). $50 \mu \mathrm{L}$ of the varied AuNPs/IP 6 and $50 \mu \mathrm{L}$ of $S$. aureus $(1 \times$ $10^{5} \mathrm{cfu} / \mathrm{mL}$ grown for $18 \mathrm{~h}$ at $37^{\circ} \mathrm{C}$ ) were placed in $1.5 \mathrm{~mL}$ microcentrifuge tubes and mixed well. Then $5 \mu \mathrm{L}$ of each sample was dropped on the aluminum sheet. Raman spectra in the range of 600 and $900 \mathrm{~cm}^{-1}$ were evaluated for these 6 samples. Intensity of the Raman signal at $733 \mathrm{~cm}^{-1}$ (SERS signal from the cell wall of $S$. aureus) for the samples was further investigated, as shown in Figure 8.

2.7. Characterization Analysis of AuNPs/IP $P_{6}$. The interaction between AuNPs and $\mathrm{IP}_{6}$ samples were analyzed by X-ray photoelectron spectroscope (XPS, VG ESCA Scientific, Theta Probe) and surface electric properties of AuNPs/ $/ \mathrm{IP}_{6}$ samples were analyzed by zeta potential analyzer (Nano S90, Malvern Instruments) as described below.

\section{Results and Discussions}

3.1. Characterization of AuNPs. LSPR wavelength and colors of solutions displayed different pattern of adsorption as shown in Figure 1. Gold colloids of various $\mathrm{IP}_{6}$ concentrations displayed various colors (Figures $1(\mathrm{a})-1(\mathrm{~g})$ ). Solutions A0 to A2 displayed brick red color or high concentration of AuNPs, A3 exhibited purple red color, A4 and A5 displayed blue color, and A6 showed purple color. UV/Vis spectroscopy showed a strong single absorption peak of the AuNPs/IP 6 and absorbed wavelength of the major peak gradually increases (red-shift) from $525 \mathrm{~nm}$ (A0) to $534 \mathrm{~nm}$ (A3) (Table 2; Figures 1(a) to 1(c)), implying that the diameter of the spherical AuNPs was about $30 \mathrm{~nm}$ and the color of Au colloids is brick red. Moreover, the peaks of A1 and A3 were sharper than the peak of $\mathrm{A} 0$; thereby the morphology and diameter of AuNPs are more homogeneous than AuNPs

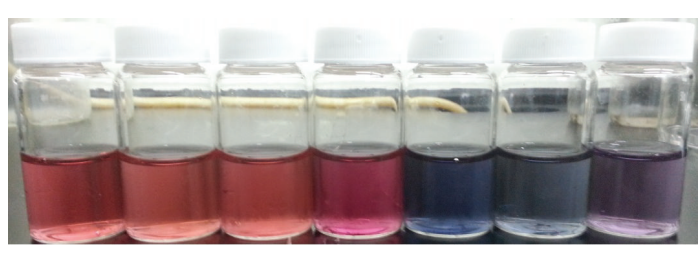
(a)
(b)
(c)
(d)
(e)
(f)
(g)

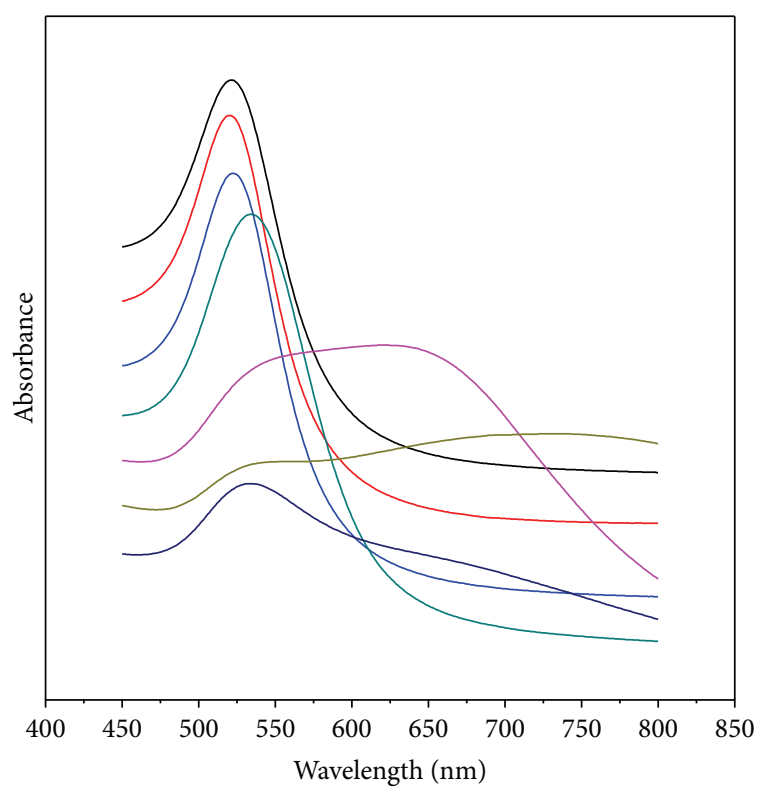

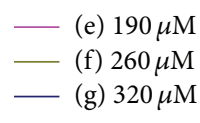

(h)

FIGURE 1: Effect of $\mathrm{IP}_{6}$ concentration on the color of AuNPs/IP 6 solutions. (a) A0, (b) A1, (c) A2, (d) A3, (e) A4, (f) A5, (g) A6, and (h) UV/Visible spectra.

without $\mathrm{IP}_{6}$. Figures $1(\mathrm{e})$ and $1(\mathrm{f})$ showed 2 peaks and implied that AuNPs display anisotropic structures. The first peak with lower wavelength was fraction of transverse absorption and the second peak with higher wavelength was longitudinal absorption. Further analysis by TEM also confirmed that both of them are irregular shaped AuNPs. 


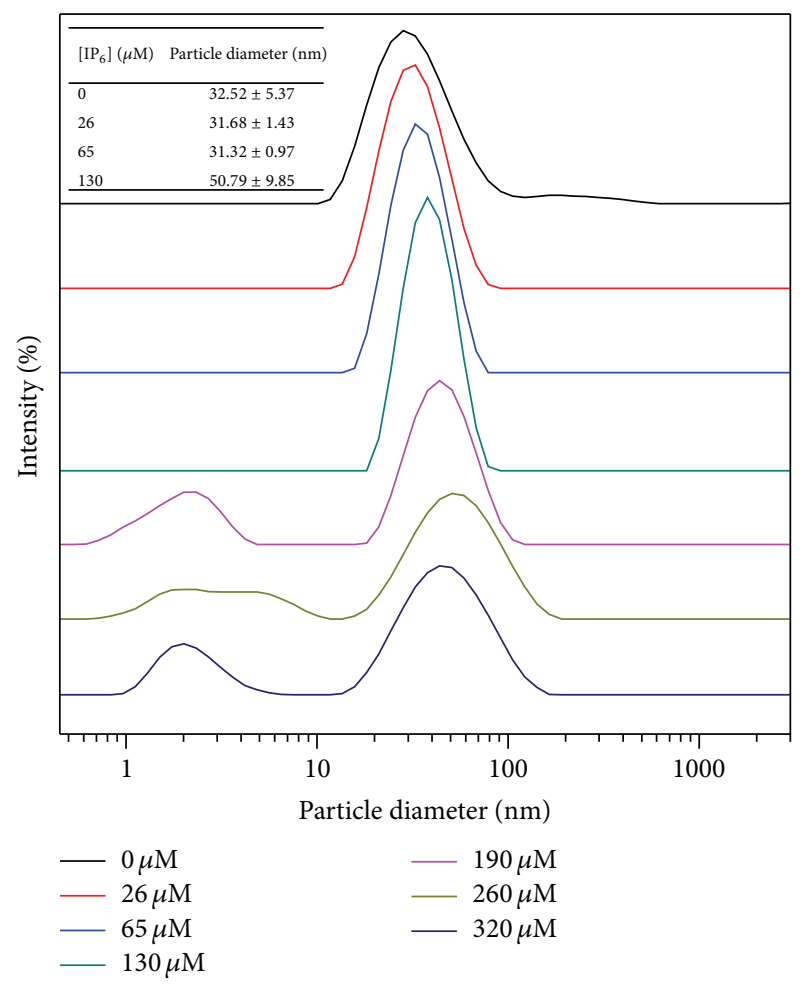

FIGURE 2: Effect of concentrations of $\mathrm{IP}_{6}$ on the size distributions of AuNPs/IP ${ }_{6}$.

TABLE 3: Dependence of exhausted time of $\mathrm{HAuCl}_{4} / \mathrm{IP}_{6}$ on the concentration of $\mathrm{IP}_{6}$.

\begin{tabular}{lccc}
\hline Sample & $\begin{array}{c}{\left[\mathrm{IP}_{6}\right]} \\
(\mu \mathrm{M})\end{array}$ & $\begin{array}{c}\text { Exhausted time } \\
(\text { min. })\end{array}$ & $\mathrm{pH}$ \\
\hline A1 & 26 & 12 & 3.51 \\
$\mathrm{~A} 2$ & 65 & 20 & 3.73 \\
$\mathrm{~A} 3$ & 130 & 30 & 4.42 \\
$\mathrm{~A} 4$ & 190 & 80 & 6.05 \\
$\mathrm{~A} 5$ & 260 & 150 & 7.29 \\
A6 & 320 & 310 & 8.72 \\
\hline
\end{tabular}

3.2. DLS Analysis of the Gold Colloids. DLS measurements of the particle diameter from $\mathrm{A} 0, \mathrm{~A} 1$, and $\mathrm{A} 2$ were $32.52 \pm 5.37$, $31.68 \pm 1.43$, and $31.32 \pm 0.97 \mathrm{~nm}$, respectively (Figure 2 ). This result agreed with the results of UV/Vis spectra for being spherical shaped. Since the smallest standard deviation of the particle diameter was from A2, the AuNPs with $65 \mu \mathrm{M}$ of $\mathrm{IP}_{6}$ showed more uniform morphology and diameter as compared to the traditional process of thermal citrate reduction method without addition of $\mathrm{IP}_{6}$.

3.3. TEM Analysis of the Gold Colloids. The IP 6 layer can clearly be observable in Figures 3(b) and 3(c), especially in Figure 3(c) for A2. There are two absorption peaks shown in samples A4 and A5 (Figures 1(e) and 1(f)); the second absorption peak was observed at 648 and $725 \mathrm{~nm}$, respectively. This indicates that AuNPs/ $\mathrm{IP}_{6}$ formed irregular structures [14-16], which was also observable in the TEM images (Figures 3(e) and 3(f)). There are many oval and prism shaped AuNPs. TEM and DLS results showed that the irregular nanoparticles were observed as the concentrations of $\mathrm{IP}_{6}$ increased from $190 \mu \mathrm{M}$ to $260 \mu \mathrm{M}$. The morphology of AuNPs changed to spherical structures again when the concentrations of $\mathrm{IP}_{6}$ reached $320 \mu \mathrm{M}$, which displays a small second peak at $655 \mathrm{~nm}$ and just little irregular shaped AuNPs were found.

3.4. Exhausted Time and Initial Reaction Rate of Gold Colloids. The reason why the morphology of AuNPs became irregularly shaped when the concentration of $\mathrm{IP}_{6}$ reaches 190 and $260 \mu \mathrm{M}$ was because $\mathrm{IP}_{6}$ is a basic salt and served as a " $\mathrm{pH}$ mediator." It can change the $\mathrm{pH}$ of auric acid solutions, leading to the growth of irregular shaped AuNPs. Higher concentration of $\mathrm{IP}_{6}$ caused the $\mathrm{pH}$ of the solution to increase and $\left[\mathrm{AuCl}_{4}\right]^{-}$is converted to a less reactive $\left[\mathrm{AuCl}_{x}(\mathrm{OH})_{4-x}\right]^{-}$. Therefore at higher $\mathrm{pH},\left[\mathrm{OH}^{-}\right]$will increase and react with $\left[\mathrm{AuCl}_{4}\right]^{-}$, forming a less reactive $\left[\mathrm{AuCl}_{x}(\mathrm{OH})_{4-x}\right]^{-}$ substance. Therefore higher concentration $\mathrm{IP}_{6}$ will cause the exhausted time of $\mathrm{HAuCl}_{4} / \mathrm{IP}_{6}$ to increase. As shown in Figure 4 and Table 3, the exhausted time increased greatly with the addition of 190 and $260 \mu \mathrm{M}$ of $\mathrm{IP}_{6}$, as compared to the addition of the $26 \sim 130 \mu \mathrm{M}$ of $\mathrm{IP}_{6}$. The calculation method for temporal evolution curve of $\mathrm{HAuCl}_{4}$ concentration used at least eight concentration points for each reaction into a Taylor expansion polynomial (average $R$-squared value for all reactions in Figure 4 is 98\%) [17]. The formation of irregular shaped AuNPs is probably caused by the following: (1) AuCl under high concentration of $\mathrm{IP}_{6}$ was not reactive enough to produce AuNPs and might go through nucleation twice to cause aggregation; (2) $\mathrm{IP}_{6}$ attached to specific surface of $\mathrm{Au}$ seeds and induced $\mathrm{AuCl}$ to grow on the specific surface of $\mathrm{Au}$ seeds leading to the formation of irregular AuNPs.

Figure 5 shows that with the addition of 26 and $65 \mu \mathrm{M}$ of $\mathrm{IP}_{6}$, the initial reaction rate was much faster as compared to $0 \mu \mathrm{M}$ of $\mathrm{IP}_{6}$; therefore $\mathrm{HAuCl}_{4}$ can be exhausted immediately to develop spherical shaped AuNPs. With the addition of 190 and $260 \mu \mathrm{M}$ of $\mathrm{IP}_{6}$, the initial reaction rate was slower than those of $0 \sim 130 \mu \mathrm{M}$ of $\mathrm{IP}_{6}$, because the reactivity of auric salt decreased with the increasing of $\mathrm{pH}$ of the solution $[18,19]$ due to increase of $\mathrm{IP}_{6}$ concentration. With the addition of $320 \mu \mathrm{M}$ of $\mathrm{IP}_{6}$, the initial reaction rate was very low and the extremely slow reaction rate caused the formation of some spherical shaped AuNPs once again.

Figure 6 illustrates our hypotheses explaining the effect of $\mathrm{IP}_{6}$ concentration on the morphology of AuNPs. 26 and $65 \mu \mathrm{M}$ of $\mathrm{IP}_{6}$ caused the reaction to develop faster as compared to formation of AuNPs without the addition of $\mathrm{IP}_{6}$. With the addition of 190 and $260 \mu \mathrm{M}$ of $\mathrm{IP}_{6}$, the formation of AuNPs is slow along with formation of irregular shaped AuNPs as mentioned in Section 3.4. When the concentrations of $\mathrm{IP}_{6}$ were increased to $320 \mu \mathrm{M}$, some AuNPs spherical structures were formed (Figure $3(\mathrm{~g})$ ). This is because of extreme slow reaction rate causing $\mathrm{Au}$ seeds to form slowly and therefore there is less formation of second nucleation or aggregation of AuNPs. 


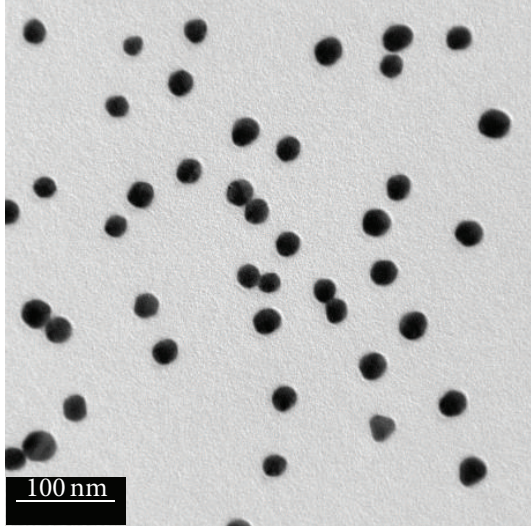

(a)

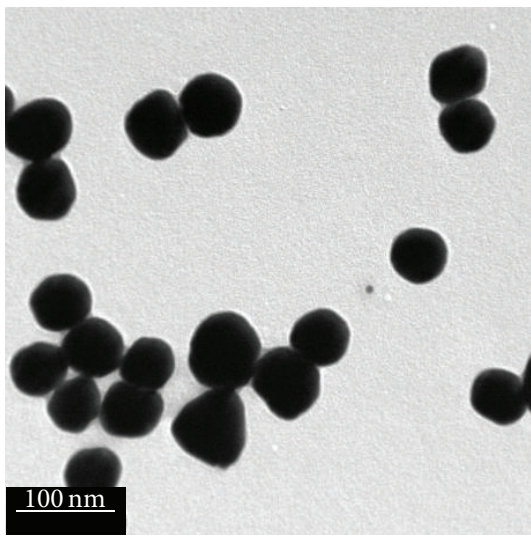

(d)

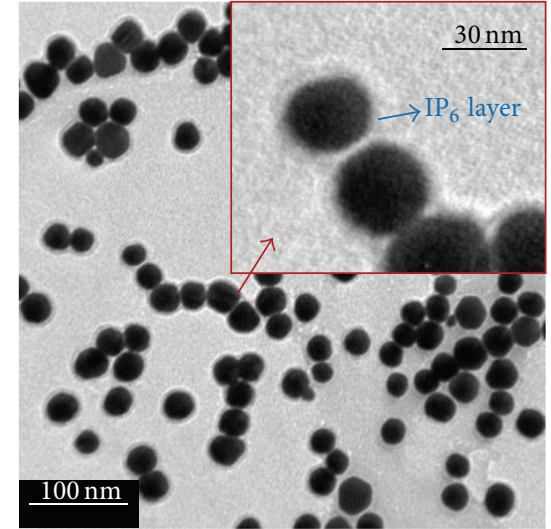

(b)

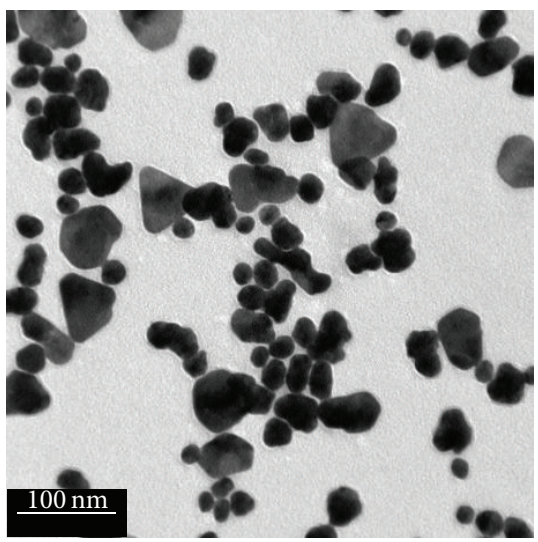

(e)

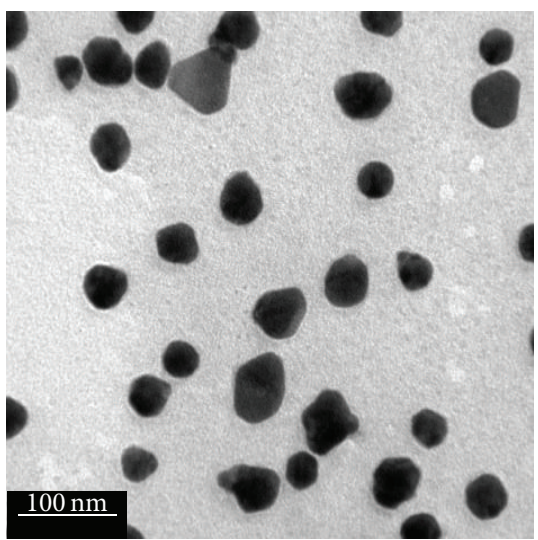

(g)

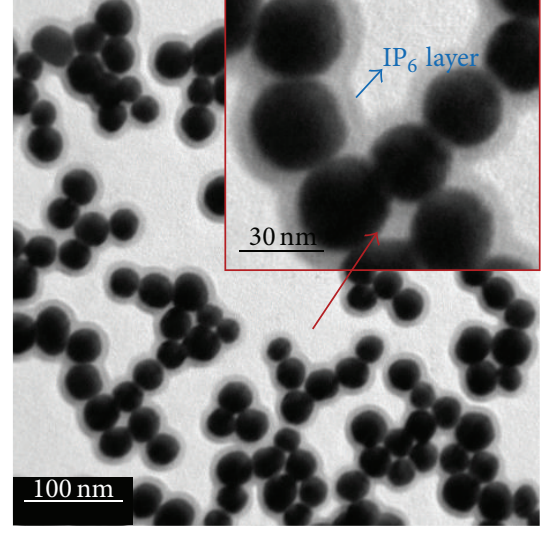

(c)

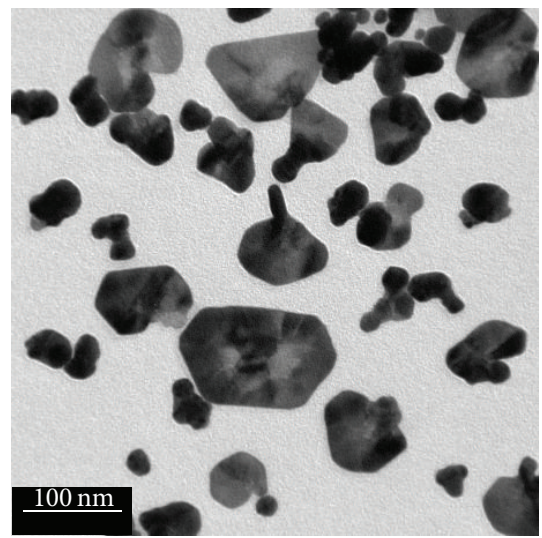

(f)

Figure 3: TEM images of AuNPs/IP ${ }_{6}$ in different concentrations of IP 6 : (a) $0 \mu \mathrm{M}$, (b) $26 \mu \mathrm{M}$, (c) $65 \mu \mathrm{M}$, (d) $130 \mu \mathrm{M}$, (e) $190 \mu \mathrm{M}$, (f) $260 \mu \mathrm{M}$, and (g) $320 \mu \mathrm{M}$.

3.5. SERS Application of AuNPs/IP $P_{6}$. Figure 7 shows the SERS spectra of $S$. aureus using AuNPs/IP 6 . The SERS peak at $733 \mathrm{~cm}^{-1}$ was from the cell wall of $S$. aureus and the strongest enhancement was observed for A2 as shown in Figure 7. Figure 7 also shows that A2 exhibits the strongest SERS intensity, which was $280040 \pm 74600$ and was about 40 times that of A0 $(7705 \pm 3295)$. Therefore the AuNPs reduced with the presence of $65 \mu \mathrm{M}$ of $\mathrm{IP}_{6}$ would enhance the SERS signal more than that without the addition of $\mathrm{IP}_{6}$. This is also confirmed with the TEM images in Figure 3, where the addition of $65 \mu \mathrm{M}$ of $\mathrm{IP}_{6}$ produced most visible $\mathrm{IP}_{6}$ layer formed on the surface of AuNPs. This core-shell structure not only made AuNPs disperse well but also led to a specific distance of 1-2 $\mathrm{nm}$ between AuNPs. This is the reason why A2 greatly increased the intensity of the Raman signal by detecting $S$. aureus. 


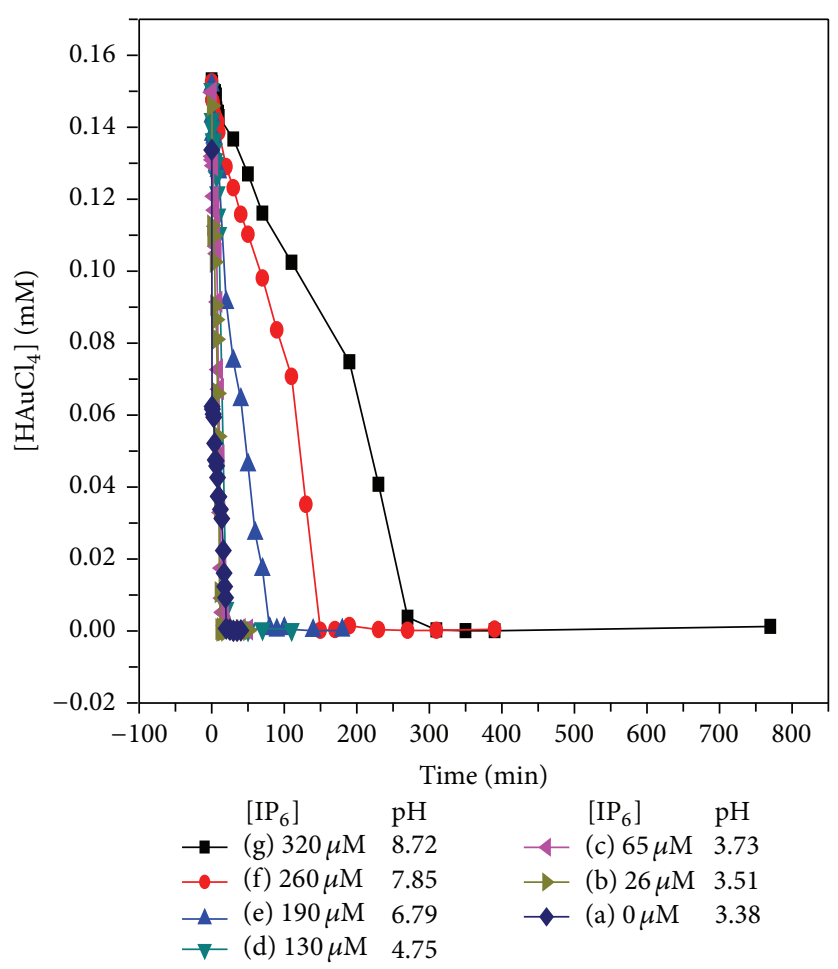

FIgURE 4: Temporal evolution of $\mathrm{HAuCl}_{4}$ concentration for the reaction with different $\mathrm{IP}_{6}$ concentrations as labeled.

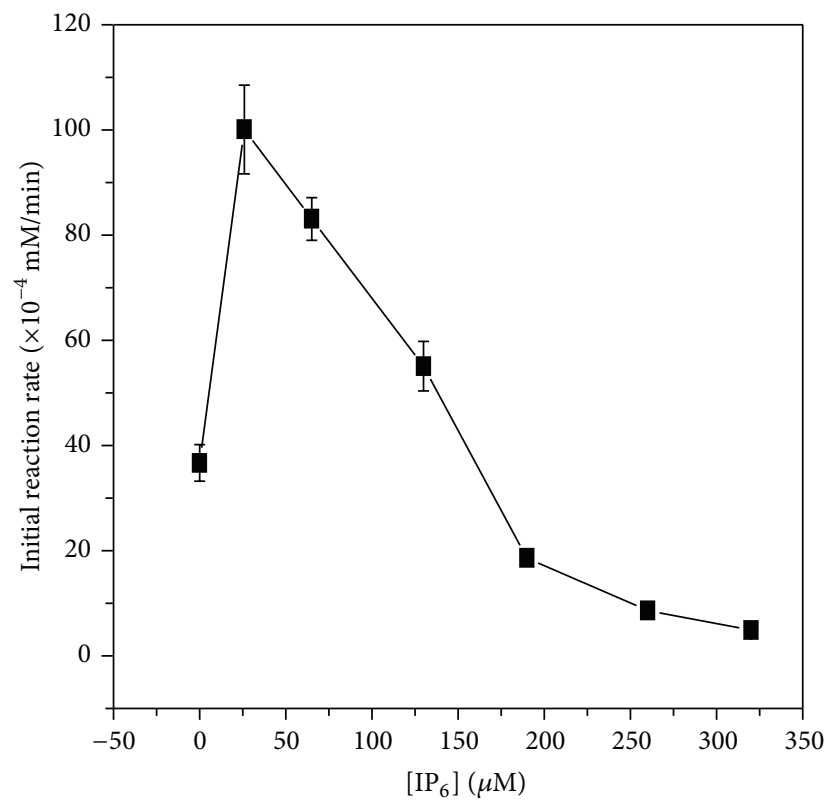

FIGURE 5: Effect of $\mathrm{IP}_{6}$ concentration on the initial reaction rates of $\mathrm{HAuCl}_{4}$.

3.5.1. Zeta Potential and XPS Analysis of AuNPs/IP 6 . The interaction between AuNPs and $\mathrm{IP}_{6}$ was further investigated by zeta potential and XPS analysis, as shown in Figure 10. Figure 9 shows that the zeta potential decreased from $-42.9 \pm$ 2.15 to $-54.83 \pm 1.22 \mathrm{mV}$ when the concentrations of $\mathrm{IP}_{6}$ increased from 0 to $65 \mu \mathrm{M}$. Thus the negative charge on the surface of AuNPs increased with increasing $\mathrm{IP}_{6}$ concentrations and higher $\mathrm{IP}_{6}$ will induce more $\mathrm{IP}_{6}$ molecules absorbed on the surface of AuNPs. XPS analysis showed $0.4 \mathrm{eV}$ and $0.3 \mathrm{eV}$ binding energy shifting of $\mathrm{Au}_{7 / 2}$ (84.5 to 84.9) and $\mathrm{Au}_{5 / 2}$ (88.1 to 88.4) from $0 \mu \mathrm{M}$ to $65 \mu \mathrm{M}$ of $\mathrm{IP}_{6}$ addition, respectively. This showed that $\mathrm{IP}_{6}$ interacted with $\mathrm{Au}^{+} \mathrm{NPs}$ 


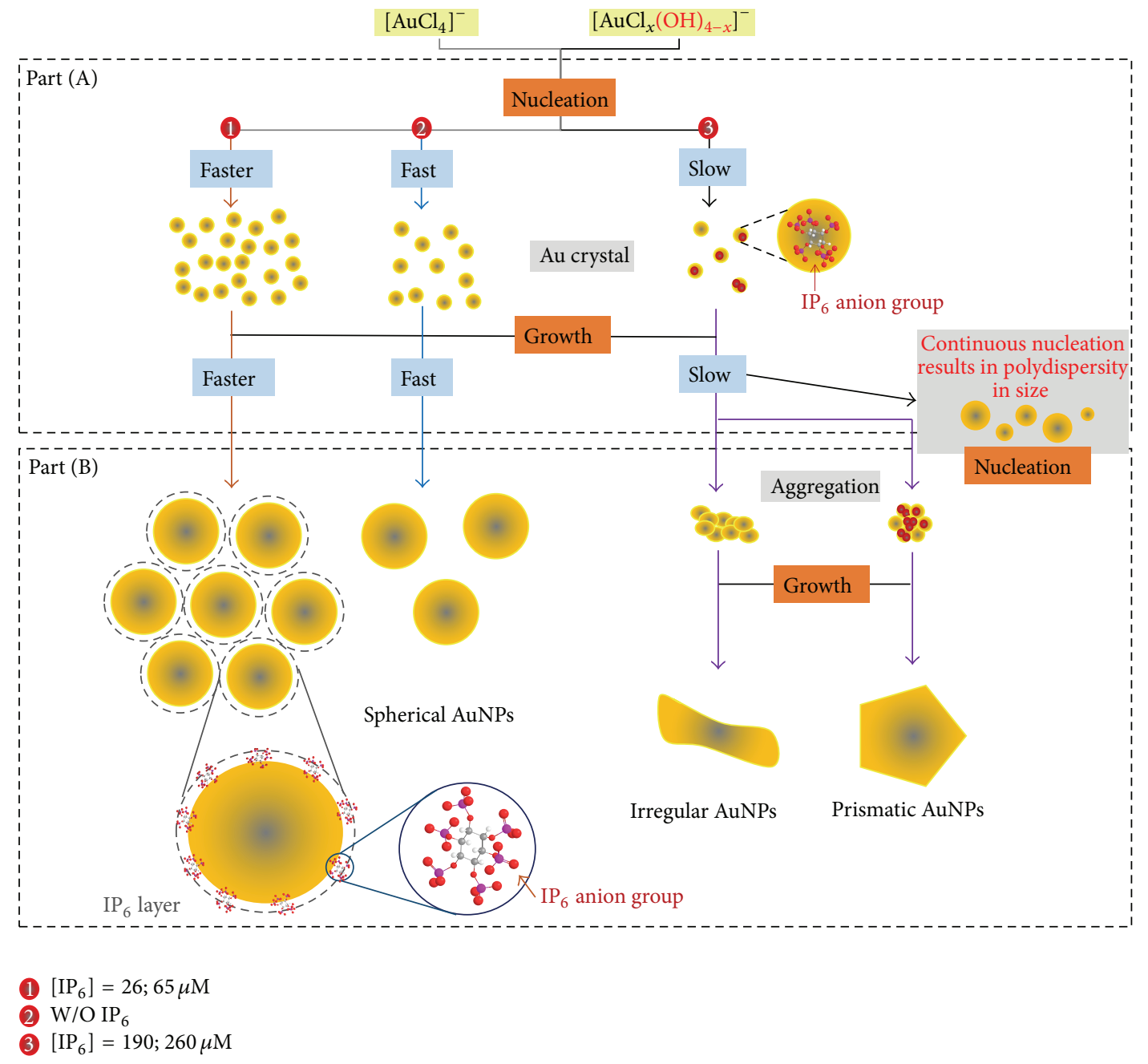

FIgURE 6: The mechanism of AuNPs formation with different $\mathrm{IP}_{6}$ concentration.

by electrostatic force. Therefore, $\mathrm{IP}_{6}$ definitely formed a layer on the surface of AuNPs with $65 \mu \mathrm{M}$ of $\mathrm{IP}_{6}$. This layer not only controlled the interparticle gaps of AuNPs within 1-2 nm from each other but also produced huge "hot spots" effect which greatly increased the Raman intensity of the sample molecules.

Zeta potential and XPS analysis indicated that $65 \mu \mathrm{M}$ of $\mathrm{IP}_{6}$ was an ideal concentration leading to formation of $\mathrm{IP}_{6}$ layer on the surface of AuNPs. The $\mathrm{IP}_{6}$ layer not only kept AuNPs within a specific interparticle distance (1$2 \mathrm{~nm}$ ) by ionic force, it also increased dispersion of AuNPs. On the other hand, irregular AuNPs or prismatic AuNPs formed with $190 \mu \mathrm{M}$ and $260 \mu \mathrm{M}$ of $\mathrm{IP}_{6}$. Thus in addition to improve the monodispersity of these anisotropic structures, irregular AuNPs can also be produced by adjusting the $\mathrm{IP}_{6}$ concentration.

In summary, A2 showed more uniform morphology and diameter as compared to A0. A2 exhibited nanoscale interparticle gaps (1-2 nm) between AuNPs, thereby producing very huge "hot spots" effect, leading to greater enhancement of SERS signal. This is a convenient way to fabricate welldispersed AuNPs, which exhibited interparticle distance of $\sim 1-2 \mathrm{~nm}$, while providing excellent biocompatibility. Therefore, $65 \mu \mathrm{M}$ of $\mathrm{IP}_{6}$ bound to AuNPs has great potential for further industrial application of SERS biosensing of bacteria or cancer cells.

\section{Conclusion}

The core-shell structure of AuNPs/IP 6 nanohybrids was successfully in situ synthesized by modified Frens method, which was applied in the rapid SERS detection of bacteria. In particular, by reducing $\mathrm{HAuCl}_{4}$ in $65 \mu \mathrm{M}$ of $\mathrm{IP}_{6}$, the morphology and distribution of AuNPs were greatly improved as compared to the AuNPs without $\mathrm{IP}_{6}$. Furthermore, AuNPs formed in $65 \mu \mathrm{M}$ of $\mathrm{IP}_{6}$ exhibited enormous "hot spots" effect, leading to greater enhancement of SERS signal. Thus, our works demonstrated a convenient way to fabricate well-dispersed AuNPs that can induce outstanding SERS enhancement that is applicable for label-free detection and biodetection of microbes and cancerous cells. 


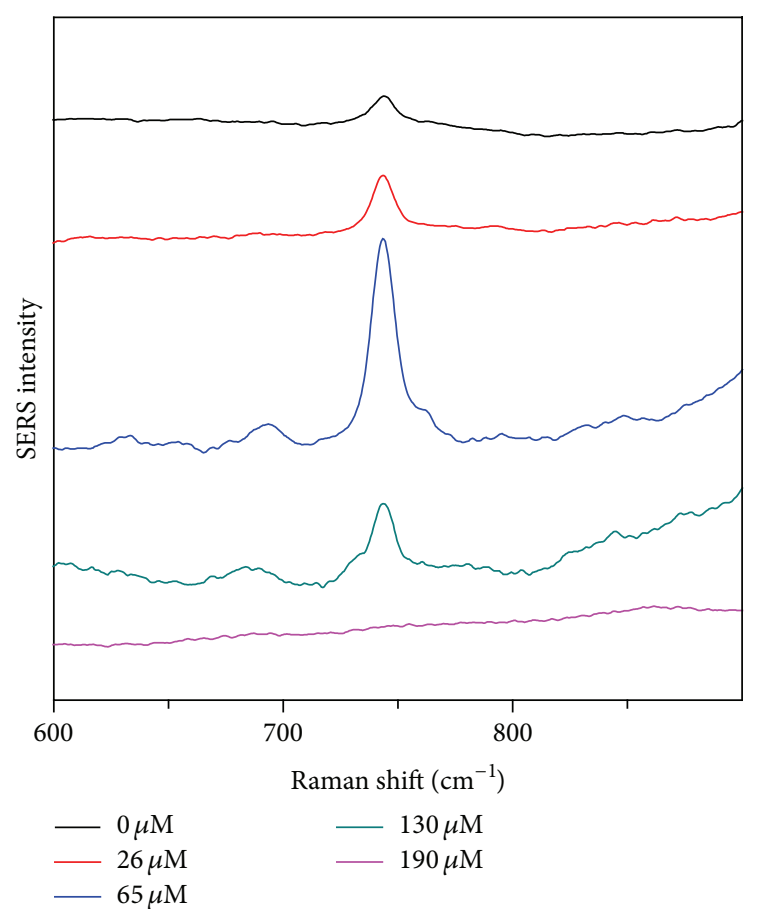

FIGURE 7: SERS spectra of $S$. aureus using different $\mathrm{IP}_{6}$ concentration of AuNPs.

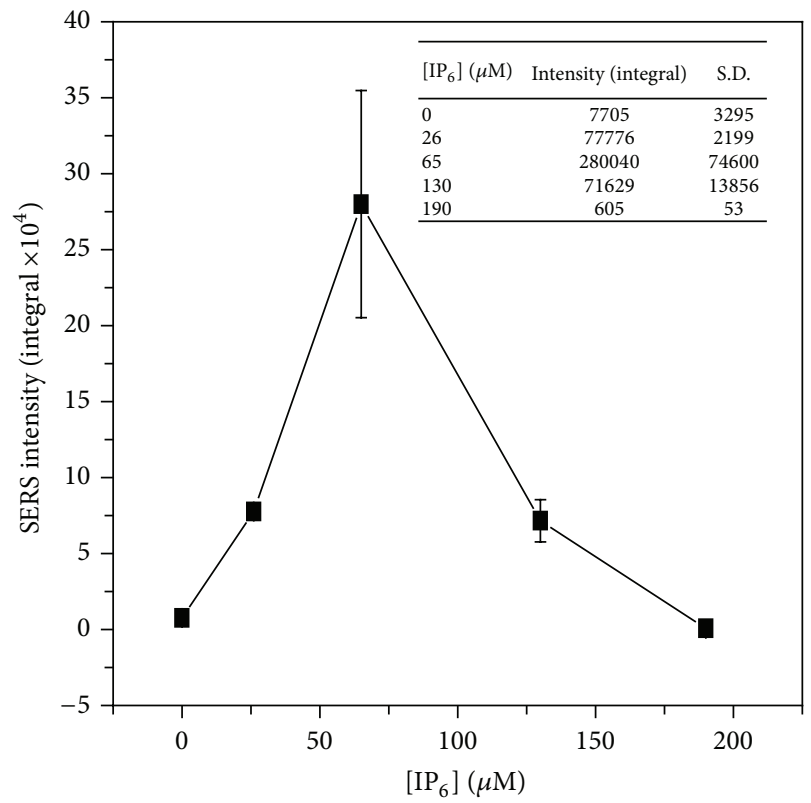

FIGURE 8: The effect of $\mathrm{IP}_{6}$ concentration on the SERS intensity at $733 \mathrm{~cm}^{-1}$ of $S$. aureus.

\section{Conflict of Interests}

The authors declare no competing financial interests.

\section{Authors' Contribution}

The paper was written by contributions of all authors. All authors have given approval for the final version of the paper.

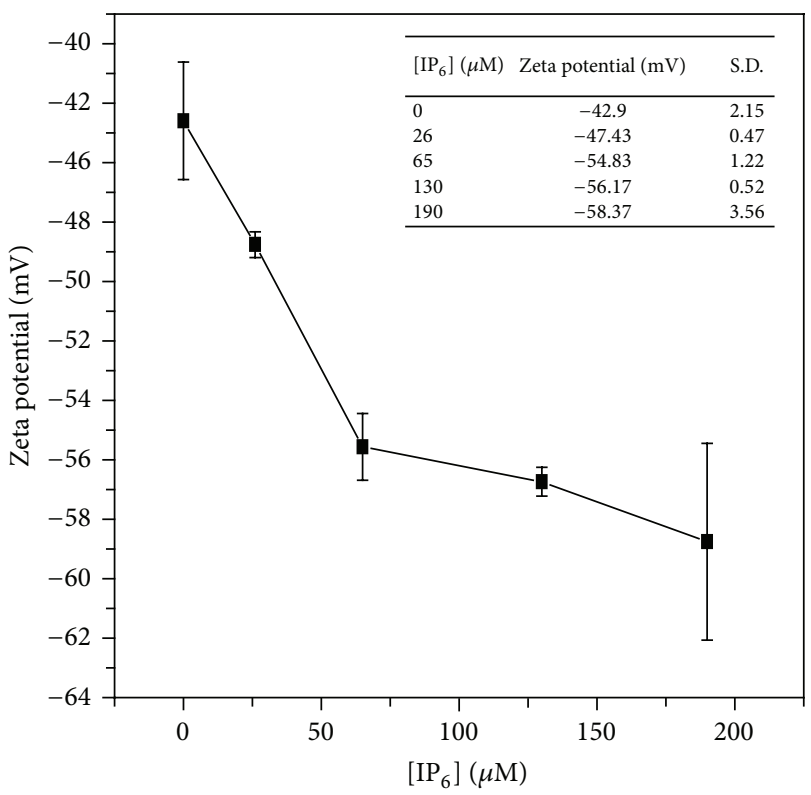

FIgURE 9: Effect of $\mathrm{IP}_{6}$ concentration on the zeta potential of AuNPs/IP ${ }_{6}$.

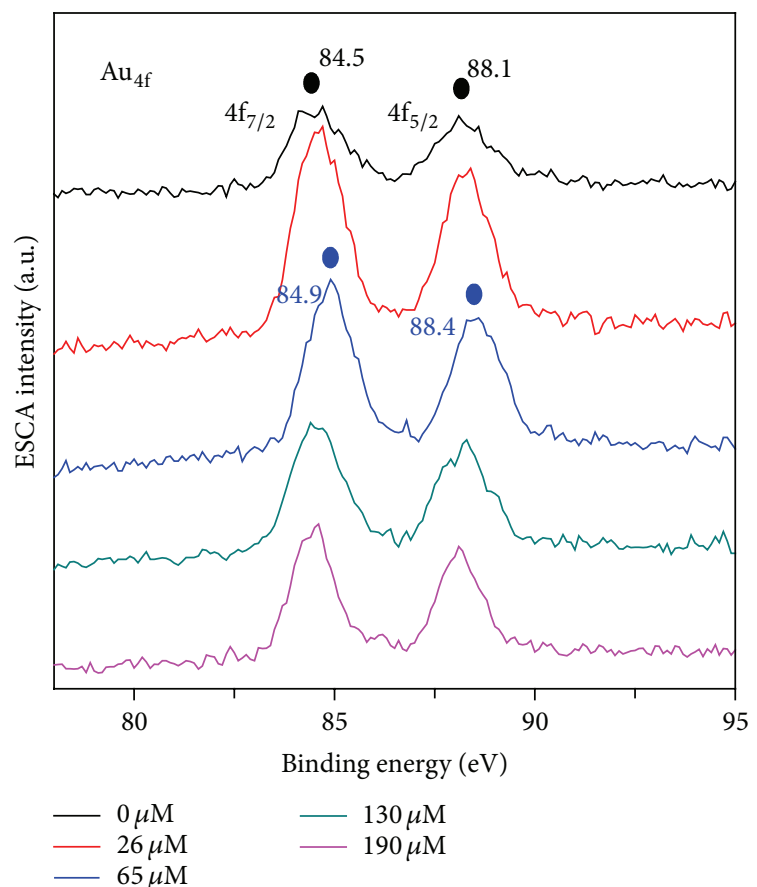

FIGURE 10: Effect of $\mathrm{IP}_{6}$ concentration on the XPS spectra of AuNPs/ $/ \mathrm{IP}_{6}$.

\section{Acknowledgments}

This work was financially supported by Ministry of Science and Technology of Taiwan (MOST 103-2628-M-001-002 and MOST 103-2221-E-131-019). The authors also thank National Taiwan University for allowing them to use their TEM Lab in order to obtain TEM images for this experiment. 


\section{References}

[1] M. Fleischmann, P. J. Hendra, and A. J. McQuillan, "Raman spectra of pyridine adsorbed at a silver electrode," Chemical Physics Letters, vol. 26, no. 2, pp. 163-166, 1974.

[2] E. Hao and G. C. Schatz, "Electromagnetic fields around silver nanoparticles and dimers," Journal of Chemical Physics, vol. 120, no. 1, pp. 357-366, 2004.

[3] P. G. Etchegoin and E. C. le Ru, "A perspective on single molecule SERS: current status and future challenges," Physical Chemistry Chemical Physics, vol. 10, no. 40, pp. 6079-6089, 2008.

[4] J. P. Camden, J. A. Dieringer, Y. Wang et al., "Probing the structure of single-molecule surface-enhanced Raman scattering hot spots," Journal of the American Chemical Society, vol. 130, no. 38, pp. 12616-12617, 2008.

[5] N. R. Jana, L. Gearheart, and C. J. Murphy, "Seeding growth for size control of $5-40 \mathrm{~nm}$ diameter gold nanoparticles," Langmuir, vol. 17, no. 22, pp. 6782-6786, 2001.

[6] L. Pei, K. Mori, and M. Adachi, "Formation process of twodimensional networked gold nanowires by citrate reduction of $\mathrm{AuCl}_{4}$ - and the shape stabilization," Langmuir, vol. 20, no. 18, pp. 7837-7843, 2004.

[7] C. J. Murphy, A. M. Gole, S. E. Hunyadi, and C. J. Orendorff, "One-dimensional colloidal gold and silver nanostructures," Inorganic Chemistry, vol. 45, no. 19, pp. 7544-7554, 2006.

[8] A. M. Michaels, J. Jiang, and L. Brus, "Ag nanocrystal junctions as the site for surface-enhanced raman scattering of single rhodamine 6G molecules," Journal of Physical Chemistry B, vol. 104, no. 50, pp. 11965-11971, 2000.

[9] L. L. Zhao, L. Jensen, and G. C. Schatz, "Surface-enhanced raman scattering of pyrazine at the junction between two Ag 20 nanoclusters," Nano Letters, vol. 6, no. 6, pp. 1229-1234, 2006.

[10] T. A. Taton, C. A. Mirkin, and R. L. Letsinger, "Scanometric DNA array detection with nanoparticle probes," Science, vol. 289, no. 5485, pp. 1757-1760, 2000.

[11] A. G. Tkachenko, H. Xie, D. Coleman et al., "Multifunctional gold nanoparticle-peptide complexes for nuclear targeting," Journal of the American Chemical Society, vol. 125, no. 16, pp. 4700-4701, 2003.

[12] X. Zhu, H. Yang, N. Wang et al., "A facile method for preparation of gold nanoparticles with high SERS efficiency in the presence of inositol hexaphosphate," Journal of Colloid and Interface Science, vol. 342, no. 2, pp. 571-574, 2010.

[13] X. Ji, X. Song, J. Li, Y. Bai, W. Yang, and X. Peng, "Size control of gold nanocrystals in citrate reduction: the third role of citrate," Journal of the American Chemical Society, vol. 129, no. 45, pp. 13939-13948, 2007.

[14] E. Hao, R. C. Bailey, G. C. Schatz, J. T. Hupp, and S. Li, "Synthesis and optical properties of 'Branched' gold nocrystals," Nano Letters, vol. 4, no. 2, pp. 327-330, 2004.

[15] C. Burda, X. Chen, R. Narayanan, and M. A. El-Sayed, "Chemistry and properties of nanocrystals of different shapes," Chemical Reviews, vol. 105, no. 4, pp. 1025-1102, 2005.

[16] S. S. Shankar, S. Bhargava, and M. Sastry, "Synthesis of gold nanospheres and nanotriangles by the turkevich approach," Journal of Nanoscience and Nanotechnology, vol. 5, no. 10, pp. 1721-1727, 2005.

[17] C.-H. Kuo, T.-F. Chiang, L.-J. Chen, and M. H. Huang, "Synthesis of highly faceted pentagonal- and hexagonal-shaped gold nanoparticles with controlled sizes by sodium dodecyl sulfate," Langmuir, vol. 20, no. 18, pp. 7820-7824, 2004.
[18] J. A. Peck, C. D. Tait, B. I. Swanson, and G. E. Brown Jr., "Speciation of aqueous gold(III) chlorides from ultraviolet/visible absorption and Raman/resonance Raman spectroscopies," Geochimica et Cosmochimica Acta, vol. 55, no. 3, pp. 671-676, 1991.

[19] D. V. Goia and E. Matijević, "Tailoring the particle size of monodispersed colloidal gold," Colloids and Surfaces A: Physicochemical and Engineering Aspects, vol. 146, pp. 139-152, 1999. 

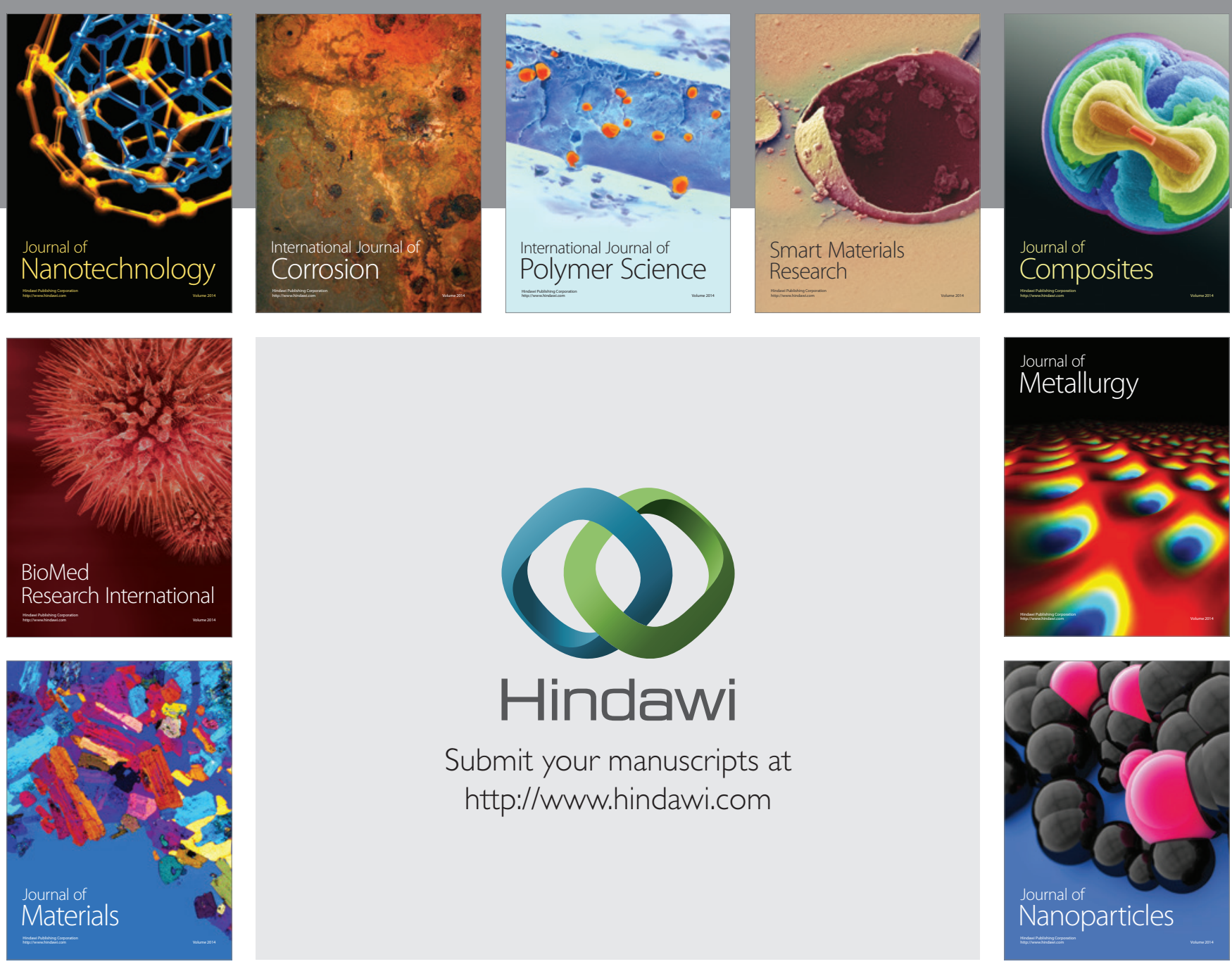

Submit your manuscripts at http://www.hindawi.com
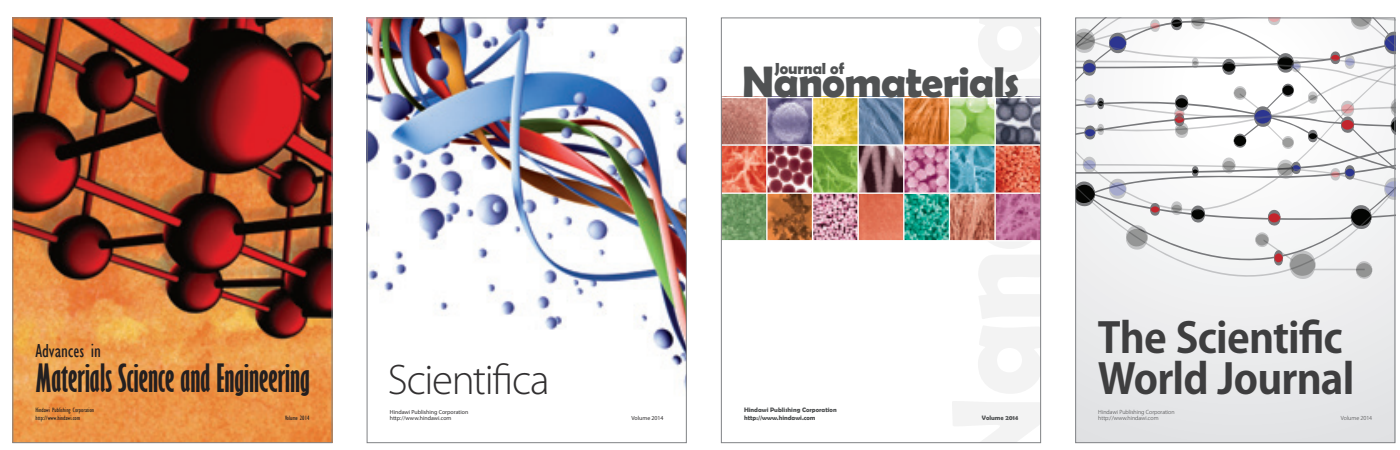

\section{The Scientific World Journal}
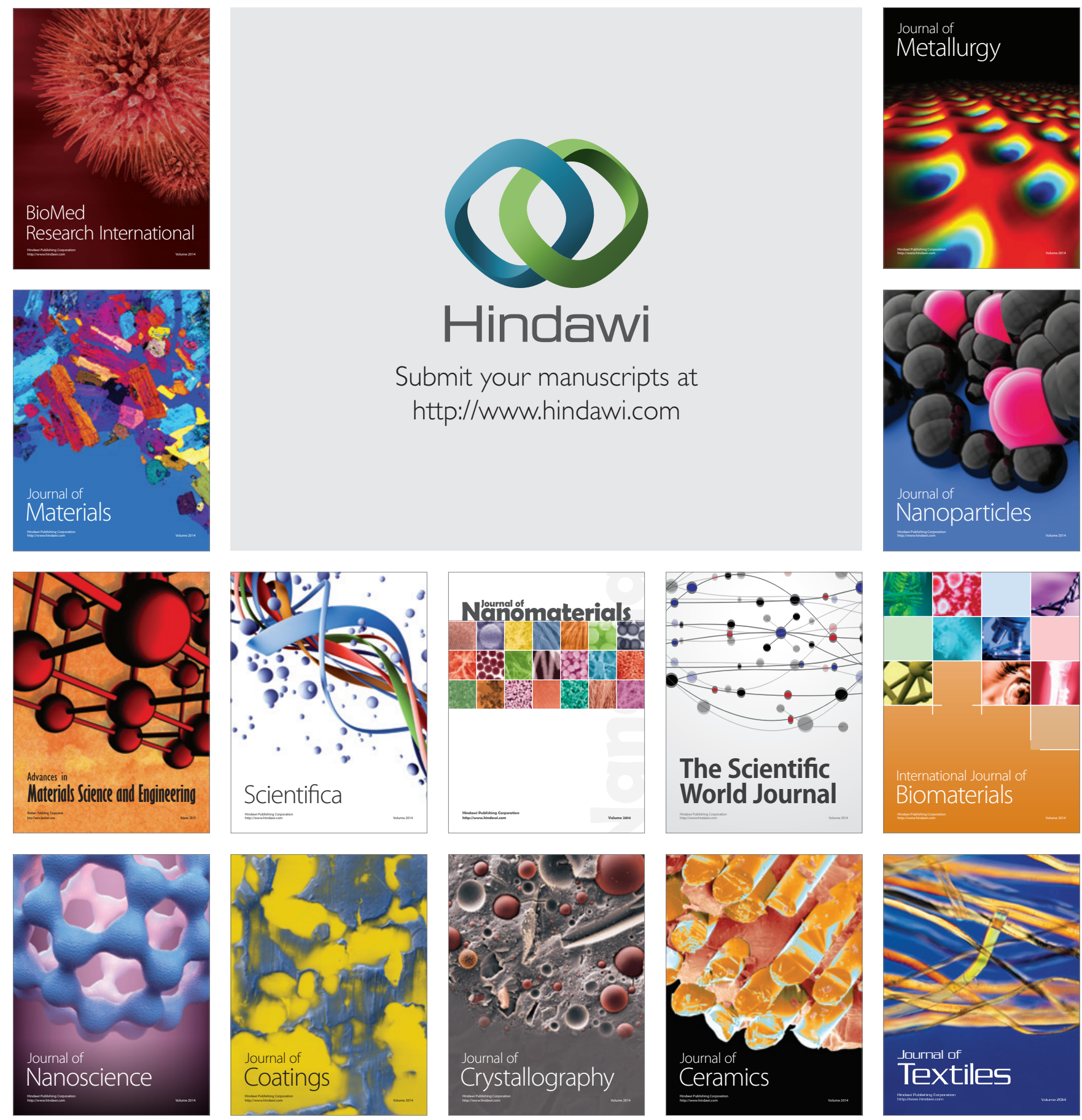